\title{
Organizational culture and the creation of a dynamic environment for knowledge sharing
}

\author{
Professor Khalid Alrawi, Dr. Yakoob Hamdan, Dr. Wassan Al-Taie and Dr. Maher \\ Ibrahim
}

\author{
American University in the Emirates
}

\begin{abstract}
In this paper the researchers introduced the concept of knowledge sharing as an important ingredient in a management success. Knowledge sharing (KS) is an approach in identifying, acquiring, applying, creating, developing, preserving and measuring the knowledge of the organization. The purpose of this paper is to analyze the knowledge sharing as a crucial component of the organizational knowledge dynamics, and the organizational barriers implementation in the business environment. This study was accomplished through questionnaires that surveyed (121) companies that are located in Abu Dhabi Emirate / United Arab Emirates (UAE). Findings revealed that organizational culture and top management attitudes which based on individual perception and a managerial style have a negative relationship with the perceived benefits of knowledge. Analyses show that management initiatives highlight the fact that not all of them are necessarily successful.
\end{abstract}

Keywords: Knowledge Management, Knowledge Sharing, Knowledge Benefits, Industrial Sector, UAE

\section{INTRODUCTION}

Defining knowledge is not an easy job because it is one of those concepts that don't have a universal definition; different authors approach the concept in different perspectives and from different angles, resulting in multiple definitions. It can be looked upon as the processing of information with the main purpose of gaining understanding of the events occurring in the surrounding environment (Bratianu, and Orzea, 2010). Knowledge sharing may be considered as a practice consisting in solving problems, that is to say problems which can be solved in many different ways.A successful managers knows that employees and their knowledge make a differentiation (Alireza, et al., 2010). Therefore, top management efforts are important in implementing KS to facilitate communication between employees and this will positively influence perceived knowledge benefits. In other words, we prefer management to focus on how to proceed instead of focusing on what management want to do. When the management of the organization and employees share the same values, perceptions, and they internalize these values, the relationship between the leader and employees will be strong. An organization's culture in which the operations factors of knowledge can come to its optimum advantages lays its focus on the stimulation and exploitation of the creativity of its employees. Creating, managing and sharing knowledge is at the top of the agenda for a growing number of organizations (Chong, 2006).

Whereas the focus on how to take into account human factors in creating and sharing knowledge in order to make the process easier, the management is to consider the psychological factor rather to share knowledge only. Knowledge consists of information, technology, know-how and skills. Value and sustainability are created from the integration of these resources better than competitors (Endres et al, 2007). The knowledge sharing system aims to explicitly make 'shareable' the know-how which enables these problems to be solved. The aim of knowledge sharing is to help, mobilize critical enquiry, and thought management to influence and hopefully add value to the efforts of the managers to enhance their firms' existence in the economy (Nurcan and Rolland, 2003). Therefore, researchers believe that organization culture and management perceptions were to have a positively relationship efforts with the employees' perceptions benefits of KS. Such knowledge system are cumulative, representing generations of experience, organization's experience and know-how over a period of time in the field of business practices, and 
are well adapted to local culture and environment. Management should emphasize continuous improvement based on sharing ideas and this will bring the benefits to the organization. An organization's management should believe that employees are part on KS as well as the data side of the equation. KM only can be implemented successfully if an encouraging environment is in place and that it is collaborative or sharing towards it Song (2008). Sharing knowledge will generate continuous improvement and quality performance, and enhancing productivity through the usage of the available sources effectively and efficiently Bhatt (2001).

The objective of this paper is to develop an argument based on the review of the literature and questionnaire to understand underlying issues in knowledge sharing, and provide a perception about sharing barriers in the industrial sector in the UAE.

The Status and Application Range of Knowledge: The traditional knowledge refers to unique knowledge of the organizational environments, existing within specific conditions in business in a particular area. The development of KS system within the organization is covering the employees' and management attitudes, including management efforts to survive in a competitive environment (Gahukar, 2010).

As organization to have the right knowledge, to know the nature of knowledge to develop and share, it is crucial for such organizations to encourage the culture of sharing and learning from each other. Management influences the performance of every employee within the organizational structure and consequently affects organizational performance (Agrawal and Henderson, 2002). For Beijerse (1999), the organization culture of motivation is essential to be adopted in its hierarchy because this is important for the sharing and utilization of knowledge. In this case the organization bringing its employees into line of management attitudes and building a development way for sharing knowledge. Differentiation between firms is through its employees, their knowledge. Organizational culture is imperative factor for successful KS. For Van Der Velden (2002), the knowledge is highly dependent on our experience, beliefs, and values.

In general, culture supportive of KS is one that highly values knowledge and encourages its creation, sharing and application. Such knowledge facilitates management decisions and survival strategies in the industry and adopting a system for sustainable use of the available resources. The researchers' belief that at present, some industries adopt old techniques that needs to be gracefully acknowledged and updating. The value proposition of knowledge sharing is now stronger than ever, and cannot be looked upon as a rare competitive differentiator, but the only differentiator. Proper and timely management of traditional knowledge, combined with improved practices, would certainly be helpful in future business strategies. Therefore, sharing knowledge requires an organizational culture that encourages employees and the management to share it without fear and freely exchange their thoughts, ideas and ways of achieving objectives.

In a knowledge intensive world, organizations must develop their understanding for sharing of knowledge and utilization of networks to achieve a competitive advantage (Farooq, 2010). The organizations' management should encourage employees to give feedback to improve KS efforts. This will encourage them to contribute positively, improving creativity, encouragement for inventing innovative ideas, and improving their performance. Therefore, the management provides the general development framework of sharing for the organization and its employees. The management then addresses its business needs with the right knowledge.

A recent study by (Cohen, Nelson, and Walsh, 2002) suggests that different channels are used to transfer different kinds of knowledge. The people and technology are combined to achieve sharing and regular flow of knowledge. In a survey of various industries, data suggests that depending on the industry, different channels are of different importance. For example, $64 \%$ of respondents in the pharmaceutical industry rated meetings or conferences as "moderately" to "very" important. While $50 \%$ of respondents in the same industry rated patents as "moderately" to "very" important. $51 \%$ of respondents in the aerospace industry rated meetings or conferences to be "moderately or "very" important, by contrast, only $14 \%$ of respondents in that industry gave the same rating to patents (Alireza, et al., 2010). The idea of industry-specific transfer channels could hold true between organizations knowledge transfer, and by discipline specific.

Employees remain to play a vital role in the knowledge sharing and because of the factor and its combination with technological and organizational aspects, management initiatives fails. It was clear evident that there is the need to enhance the 
functionalities of the knowledge sharing system with dynamic ways for the construction of understanding content. The researchers believe that management in the firms surveyed did not provide adequate funds, incentives and rewards for KS implementation in order to motivate the employee to become more efficient and competence. The limitation of the knowledge sharing platform to support the organization in different modes was a major disadvantage. It is imperative for organizations to understand and develop knowledge sharing business strategies and tools.

The researchers believe that organization should shift the focus -as management efforts -from knowledge sharing to support relationships between employees and actual applying experiences of those other workers, also change working environments to encourage knowledge sharing and workplace learning and to provide time, space and instruments to do so.

Management and Perceived knowledge Benefits: Lam (2000) provides a taxonomy of knowledge at the organizational and individual level as it relates to explicit and tacit knowledge. Lam argues that there are four kinds of knowledge: 'engrained', 'embodied', 'encoded', and 'embedded.' These four kinds of knowledge are specific to the collective and the individual Knowledge transfer within the organizational hierarchy varies in measurability and accessibility. Management roles' settings and formats may influence the efficiency of knowledge sharing. Further, the expectations, personal learning style, and attitude of the participant may influence the efficiency of knowledge transfer. One assumption was that knowledge sharing is more effective with increasing levels of involvement, for example that active employees encourage greater knowledge sharing (Jan, and Michael, 2010). In this respect management motivation should be considered, and may be a field for innovations. An interesting option is to make the information accessible for participants. Such transparency is in tune with modern knowledge (Bennett, 2005).

When the information and knowledge are considered to be valuable in an organization then it must be effectively managed for the growth and development of these organizations. The researchers believe that there are some gaps between current knowledge sharing practices and what management firms' in the sample expected from knowledge sharing, and no industrial managers react identically and consequently, the organizations' endeavors in implementing knowledge sharing often emerged through activities manifested under knowledge management.

Knowledge consists of information, technology, know-how and skills. Therefore, managing knowledge means to create an environment within the organization to facilitate the creation, transfer and sharing of knowledge Drucker (1991), and Gillingham and Roberts (2006), have focused on relationship between knowledge management and the internal environment.

In a knowledge intensive world, organizations must develop their understanding for sharing of knowledge and utilization of networks to achieve a competitive advantage. Others (Alavi \& Leidner 2001, Cook \& Brown, 1999) focus on the tool of knowledge management assessment is arranged of five basic elements: strategy and leadership, culture, technology, measurement, and process. For O'Dell, and Grayson (1998), it seems the most important challenges are creation and utilization of knowledge. It is a concept deeply influenced by the personality of the holder, its beliefs, attitudes and culture (Bratianu and Orzea, 2010). To those researchers knowledge leads to innovation, learning, and creativity.

Knowledge sharing leads to faster knowledge connection with the organization that can greatly benefit from this new knowledge. Bhatt (2001) and Rowley (2000) argued that a firm may obtain competitive advantages from adopting knowledge sharing. Sveiby (2001) recognized nine knowleledge transfers/conversions for creating value in an organization.Thses values created through knowledge between the firm and others in the same industry. In the literature review, some researchers concerned with three areas in sharing knowledge: background/structural factors, knowledge production and knowledge integration, others mentioned: Staff, Information, Data, Knowledge, and Wisdom (Alireza, et al., 2010).

To achieve advantages from opportunities facilitated by information technology mainly in knowledge management application, firms need to manage information technology to achieve successful combination with its strategic goals (Nonaka, Toyama, and Nagata, 2000). Due to the development of new knowledge firms are looking into the possibility of applying corporate knowledge management systems to improve their efficiency and competition in the marketplace (Reige, 2005). In addition, most of the interviewees considered having 
some form of overview of the knowledge in the organization as important for facilitating sharing process, but management had no solutions yet for removing sharing barriers. In this research, the attempt is focused on identifying level of knowledge sharing oriented management and implementation barriers in the field of industry.

From the above discussion of the literature on knowledge sharing and transference of knowledge, we conclude that the management attitude, the firm's Culture, the firm's vision and mission, the internal environment of the firm, and employees' perceptions, reflect knowledge sharing implementation barriers in the industrial firm.

\section{METHODOLOGY AND ANALYSIS}

The present study employed survey type and involved the managers of these firms in the sample. The population of the study was selected through stratified sampling. Questionnaires were sent to the managers of 121 firms (represent more than $45 \%$ of the industrial firms, according to Abu Dhabi Chamber of Commerce, 2009 Annual Report) with significant responsibility for measuring the level of knowledge oriented management. From 121 questionnaires distributed, 112 managers completed back their questionnaires, result in $92 \%$ responses. Measures were adopted and used to weigh each of the five constructs, namely, management attitudes, firm's culture, firm's vision and mission, internal environment and employees' perceptions. The study used a five-point rating scale, i.e. from 1 (strongly disagree) to 5 (strongly agree). The research is to investigate the status of these constructed variables as barriers for knowledge sharing in industrial sector (Table 1).

From Table 1, the correlation between barriers of knowledge sharing within the firms surveyed in the sample was high and significant in 0.01 . The rank of indicators' correlation for internal environment, employees' perceptions, firm's culture, firm's vision and mission and management attitudes are: 0.619 , $0.584,0.791,0.637$, and 0.591 respectively. Firm's culture in the first rank, firm's vision and mission in the second, internal environment in the third rank, management attitudes in the forth rank and employees' perceptions is last rank. Using Cronbach alpha method, management attitudes was found 0.72 , and firm's vision and mission is the least (0.63). However such alpha value has a rather high value. The alpha value of 0.79 indicates that the research instrument enjoys a rather high validity.

Table 1: Data Information

\begin{tabular}{|l|l|l|l|l|}
\hline The Variable & $\begin{array}{l}\text { Cronbach's } \\
\text { Alpha }\end{array}$ & Mean & Correlations & Sig \\
\hline Internal Environment & 0.70 & 14.13 & 0.619 & .000 \\
\hline Employees' Perceptions & 0.72 & 15.22 & 0.584 & .000 \\
\hline Firms' Culture & 0.75 & 16.50 & 0.791 & .000 \\
\hline Firms' Vision and Mission & 0.63 & 11.2 & 0.637 & .000 \\
\hline Management Attitudes & 0.72 & 33.51 & 0.591 & .000 \\
\hline Alpha Value & & & & \\
\hline
\end{tabular}

The mean values on a five-point scale (1= strongly disagree; 5 = strongly agree) of the five indicators concerning knowledge sharing were: 12.31, 13.24, 14.52, 7.91 and 31.53 for internal environment, employees' perceptions, firms' culture, firms' vision and mission and management attitudes respectively. The mean value of management attitudes is 31.53 in the high ranking, indicating that management in the firms surveyed is using the closed door system, low participation for employees in the decision making process, and is not aware that knowledge plays a significant role in the success of the organization. Firm's culture is in the second ranking 14.52, indicated that solving organization problems through teamwork was low. This indicator is compatible with the third ranking elements, the employees' perceptions which value is 13.24. In fact, the respondents believe managers and employees in these firms are not judged enough, by what they do and the knowledge of departing employees is not passed pervasive on to successors. In fact, such issues reflects that these firms has not a suitable network of knowledge workers, further more they believe there is not an active program for developing idea. The internal environment element is in the fourth rank with value of 12.31 . From the score the clear interpretation for such situation is that the employees and their firms have been acting rather 
poorly in case of regular and wide exchange of knowledge, and using of information system and communication have been lower than average. Firms' visions and missions are in the last rank with a mean value 7.91. The lower level of value indicated that employees have had no knowledge about the missions and objectives of their firms. The mean of knowledge sharing was 111.603 , which indicated that respondents in the sample believed that management efforts for the firms in the sample for sharing knowledge between employees according to the present criteria along with the firms' internal environment was less than the average ( Table 2).

Table 2: Statistics Analysis

\begin{tabular}{|l|l|l|l|l|}
\hline Variables & Mean & Std. Deviation & Kurtosis & Skewness \\
\hline Internal Environment & 12.31 & 3.8 & -0.063 & -0.5 .21 \\
\hline Employees' Perceptions & 13.24 & 4.8 & -0.201 & -0.649 \\
\hline Firms' Culture & 14.52 & 5.1 & -0.27 & -0.749 \\
\hline Firms' Vision and Mission & 7.91 & 3.1 & -0.311 & -0.431 \\
\hline Management Attitudes & 31.53 & 7.1 & -0.077 & -0.015 \\
\hline Knowledge sharing Total & 111.603 & & & \\
& & & & \\
\end{tabular}

Through the discussion with those managers in the firms surveyed, the researchers asked respondents to elaborate on their answers. Respondents mentioned other barriers for knowledge sharing in their firms. The researchers believe that managers' education was probably behind such revelations. Barriers mentioned by those managers may be specified such as: relative low level of awareness and understanding, quality of information overall, face-toface interaction, assistance in the development of data and information (Klein, 2008), relative undeveloped database, effective means to transmit knowledge, language barrier, and the 'context' in which the knowledge has shared. To assess if the education element is behind such problems' expectations we used the Kruscal-Wallis techniques. Results are in (Table 3).

From (Table 3), results revealed that there is a relationship between firm's culture, internal environment, employees' perceptions, and total knowledge sharing with employees' and the managers' education level . With $[K \partial f=2.000, P<$ .01], the value of the construct variables are: [ $(\mathrm{K} \partial f=$

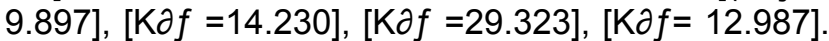
There were no significant differences between education and the other two barriers variables (i.e., management attitudes and firm's vision and mission).

Table 3: Kruscal-Wallis Test

\begin{tabular}{|l|l|l|l|l|l|l|}
\hline & $\begin{array}{l}\text { Internal } \\
\text { Environment }\end{array}$ & $\begin{array}{l}\text { Employees' } \\
\text { Perceptions }\end{array}$ & $\begin{array}{l}\text { Firms' } \\
\text { Culture }\end{array}$ & $\begin{array}{l}\text { Firms' } \\
\text { Vision and } \\
\text { Mission }\end{array}$ & $\begin{array}{l}\text { Management } \\
\text { Attitudes }\end{array}$ & $\begin{array}{l}\text { Total } \\
\text { Knowledge } \\
\text { sharing }\end{array}$ \\
\hline Chi-Square & 14.230 & 29.323 & 9.897 & 2.971 & 1.173 & 12.987 \\
\hline Asymp. Sig. & 0.000 & 0.000 & 0.006 & 0.213 & 0.689 & 0.002 \\
\hline$\partial f$ & 2.000 & 2.000 & 2.000 & 2.000 & 2.000 & 2.000 \\
\hline
\end{tabular}

\section{CONCLUSION}

This study is important for all companies in the economy especially in the industrial sector where managing knowledge is a way of doing business and achieving organizational objectives in industrial sector of the UAE economy. This paper contributes to the research in organizational learning and knowledge sharing practices by trying to identify barriers in knowledge sharing and transference within the organizations.

Results of this study suggest that the employees and their firms have been acting rather poorly in the exchange of knowledge; participants showed a rather low knowledge of their firms' strategic vision and 
management roles may be more efficient as a way of communication, responsibility and, trust within the organization, also respondents believe that both managers and employees in these firms are not judged enough, by what they do and the knowledge of departing employees is not passed pervasive on to successors. Respondents expressed that the knowledge gained was mostly theoretical. There is need for strengthening of a two-way flow of information within these firms between departments and the organizational hierarchy. Effective knowledge sharing may be achieved on organizational levels through departments' relations and through the institutionalization of such departments in the organizations framework.

These obstacles, such as management attitudes, firm's culture, firm's vision and mission, internal environment, employees' perceptions, raise problems which transcend our research. But there was a significant relationship between knowledge sharing with the employees' experience in the sample. Therefore researchers believe that organizational structure and operational process should be improved or be re-designed.

The researchers concluded that once a specific type of knowledge has been created, it requires a system and management efforts to retain and transfer such knowledge. Firm's culture and management attitudes will influence and hopefully add value to the efforts of the employees to build the knowledge sharing required for the benefits of their firms.

\section{REFERENCES}

Alireza, A., et al., (2010), Evaluating Knowledge-Oriented Management: An Iranian University Case Study, Journal of Knowledge Management Practice, Vol. 11, No. 2.2 Available At: http://WWW.tlainc.com/jmpv11n210.htm.

Agrawal, A., and Henderson, R., (2002), Putting patents in context: exploiting knowledge transfer from MIT, Management of Science, Vol. 48, No. 1, pp. 44-60.

Alavi, M., \& Leidner, E., (2001), Review: Knowledge Management and Knowledge Management Systems: Conceptual Foundations and Research Issues, MIS Quarterly, Vol. 25, No. 1, pp. 107-136.

Bratianu, C., and Orzea, I., (2010), Tacit Knowledge Sharing in Organizational Knowledge Dynamics, Journal of Knowledge Management Practice, Vol. 11, No. $2.2 \quad$ Available at: http://WWW.tlainc.com/jmpv11n210.htm.
Bennett, B., (2005), Modes of Concept Definition and Varieties of Vagueness, Applied Ontology, Vol. 1, No. 1, pp. 17-26.

Beijerse, P., (1999), Questions in Knowledge Management: Defining and Conceptualizing a Phenomenon, Journal of Knowledge Management, Vol. 3, No. 2, pp. 94-110.

Bhatt, G., (2001), Knowledge management in organizations: Examining the Interaction Between Technologies, Techniques, and People, Journal of Knowledge Management, Vol. 5, No. 1, pp. 68-75.

Bratianu, C., and Orzea, I.,(2010), Tacit Knowledge Sharing in Organizational Knowledge Dynamics, Journal of Knowledge Management Practice, Vol. 11, No. 2, June 2010. Available at: http://WWW.tlainc.com/jmpv11n210.htm.

Cohen, W., Nelson, R., and Walsh, J., (2002), Links and impacts: the influence of public research on industrial R\&D. Management Science, Vol. 48, No. 1, pp. 1-23.

Cook, D., \& Brown S., (1999), Bridging Epistemologies: The Generative Dance between Organizational Knowledge and Organizational Knowing, Organization Science, Vol. 10, No. 4, pp. 381-400.

Chong, C., (2006), Knowledge Management critical success factors: A comparison of perceived importance versus implementation in Malaysian ICT companies, The Learning Organization, Vol.13, No. 3, pp. 230-256.

Drucker, P., (1991), The New Productivity Challenge, Harvard Business Review, Vol. 69, No. 6, pp. 69-79.

Endres, L., et al., (2007) Tacit Knowledge Sharing, Selfefficacy Theory, and Application to the Open Source Community, Journal of Knowledge Management, Vol. 11, No. 3, pp. 92-103.

Farooq, M., (2010), Beyond The Tacit-Explicit Dichotomy: Towards A Conceptual Framework For Mapping Knowledge Creation, Sharing \& Networking, Journal of Knowledge Management Practice, Vol. 11, No. 2, Available at: http://WWW.tlainc.com/jmpv11n210.htm.

Gahukar, R., (2010), Intellectual Property Rights And The Management Of Traditional Knowledge In Indian Agriculture, Journal of Knowledge Management Practice, Vol. 11, No. 2, Available at: http://WWW.tlainc.com/jmpv11n210.htm.

Gillingham, H., and Roberts, B., (2006), Implementing Knowledge Management: A Practical Approach, Journal of Knowledge Management Practice, Vol. 7, No.1. Available at: http://www.tlainc.com/articl107.htm.

Jan, R., and Michael, S., (2010), An Exploratory Study On Knowledge Transfer At A University Conference, Journal of Knowledge Management Practice, Vol. 11, No. 2, Available at: http://WWW.tlainc.com/jmpv11n210.htm. 
Klein, J., (2008), Some Directions for Research in Knowledge Sharing, Knowledge Management Practice \& Research, Vol. 6, pp. $41-46$.

Lam, A., (2000), Tacit Knowledge, Organizational Learning and Societal Institutions: An Integrated Framework, Organization Studies, Vol. 21, No. 3, pp. 487-513.

Nurcan, S., and Rolland, C., (2003), A Multimethod for Defining the Organizational Change, Information Software Technol, Vol. 25, No. 2, pp. 61-82.

Nonaka, I., Toyama, R., and Nagata, A., (2000), A Firm as a Knowledge Creating Entity: A New Perspective on the Theory of the Firm', Industrial and Corporate Change, Vol. 9, No. 1, pp.1-20.

O'Dell, C., and Grayson, C., (1998), If Only We Knew What We Know: Identification and Transfer of Internal Best Practices, California Management Review, Vol. 40, No. 3, pp. 154-174.

Papoutsakis, H., and Valles, R., (2006), Linking Knowledge Management and Information Technology to Business Performance: A Literature Review and a Proposed Model, Journal of Knowledge Management Practice,
Vol. $7, \quad$ No. $1 . \quad$ Available at: http://www.tlainc.com/articl106.htm

Reige, A., (2005), Three-dozen Knowledge Sharing Barriers Managers Must Consider, Journal of Knowledge Management, Vol. 9, No. 3, pp. 18-35.

Rowley, J., (2000), Is higher Education ready for Knowledge Management? International Journal of Educational Management, Vol. 14, No. 7, pp. 325-33.

Song, H., (2008), The Effects of Learning Organization Culture on the Practices of Human KnowledgeCreation: An Empirical Research Study in Korea, International Journal of Training and Development, Vol. 12, No. 4, pp. 265-281.

Sveiby, E., (2001), A Knowledge-based Theory of the Firm To Guide Strategy Formulation, Journal of Intellectual Capital, Vol. 2, No. 4, pp. 344-58.

Van Der Velden, M., (2002), Knowledge Facts, Knowledge Fiction: The Role of ICTs in Knowledge Management For Development, Journal of International Development, Vol. 14, No. 1, pp. 25-37. 